NBER WORKING PAPER SERIES

TECHNOLOGY, INTERNATIONAL TRADE, AND POLLUTION FROM U.S. MANUFACTURING

Arik Levinson

Working Paper 13616

http://www.nber.org/papers/w13616

\author{
NATIONAL BUREAU OF ECONOMIC RESEARCH \\ 1050 Massachusetts Avenue \\ Cambridge, MA 02138 \\ November 2007
}

I am grateful to the National Center for Environmental Economics and to Resources for the Future for hosting me during parts of this research, to Mun Ho, Carl Pasurka, Jared Creason and Wayne Gray for helpful conversations and suggestions, to Jennifer Blessing for research assistance, and to Randy Becker and Wayne Gray for providing an advance copy of the updated NBER-CES Manufacturing Productivity Database. Roy Huntley and Rhonda Thompson at the EPA provided invaluable help interpreting the National Emissions Inventory. The views expressed herein are those of the author(s) and do not necessarily reflect the views of the National Bureau of Economic Research.

(C) 2007 by Arik Levinson. All rights reserved. Short sections of text, not to exceed two paragraphs, may be quoted without explicit permission provided that full credit, including $\odot$ notice, is given to the source. 
Technology, International Trade, and Pollution from U.S. Manufacturing Arik Levinson

NBER Working Paper No. 13616

November 2007

JEL No. D57,F18,Q55,Q56

\begin{abstract}
$\underline{\text { ABSTRACT }}$
Total pollution emitted by U.S. manufacturers declined over the past 30 years by about 60 percent, even though real manufacturing output increased 70 percent. This improvement must result from a combination of two trends: (1) changes in production or abatement processes ("technology"); or (2) changes in the mix of goods manufactured in the United States, which itself may result from increased net imports of pollution-intensive goods ("international trade"). I first show that most of the decline in pollution from U.S. manufacturing has been the result of changing technology, rather than changes in the mix of goods produced, although the pace of that technology change has slowed over time. Second, I present evidence that increases in net imports of pollution-intensive goods are too small to explain more than about half of the pollution reductions from the changing mix of goods produced in the United States. Together, these two findings demonstrate that shifting polluting industries overseas has played at most a minor role in the cleanup of U.S. manufacturing.
\end{abstract}

Arik Levinson

Department of Economics ICC 571

Georgetown University

3700 O St., NW

Washington, DC 20057-1036

and NBER

aml6@georgetown.edu 


\section{Technology, International Trade, and Pollution from U.S. Manufacturing}

\section{Introduction}

Total pollution emitted by U.S. manufacturers has declined over the past 30 years, by amounts ranging from 30 percent for nitrogen oxides $\left(\mathrm{NO}_{\mathrm{x}}\right)$ to 66 percent for sulfur dioxide $\left(\mathrm{SO}_{2}\right)$. At the same time, the real value of manufacturing output has increased by more than 70 percent. This cleanup can be divided into two components: (1) advances in production or abatement processes ("technology"), and (2) changes in the composition of goods manufactured in the United States. The change in industry composition can further be divided into (a) decreases in pollution-intensive goods consumed, and (b) increases in pollution-intensive goods imported ("international trade"). How much of the overall pollution reduction stems from technology, and how much from international trade?

In Part 1 of this analysis, I show that technology accounts for well over half of the overall reductions in pollution from manufacturing. In Part 2, I show that increases in net imports of polluting goods can account for - at most - half of the pollution reductions resulting from the changing composition of U.S. manufacturing (which is itself a small part of the total per Part 1). Together, these two results demonstrate that shifting polluting industries overseas has played at most a minor role in the overall cleanup of the U.S. manufacturing sector.

Allocating credit for the cleanup of manufacturing among these trends in technology and international trade is important for several reasons. Most U.S. environmental regulations have been designed explicitly to alter the technology of production, not the mix of goods produced or consumed. This paper asks whether U.S. manufacturing pollution has declined as a consequence of following the stated intent of the laws (changing technology) or as a consequence of avoiding those laws by producing overseas (international trade). More importantly, if the regulations have simply changed what gets manufactured domestically and have increased imports of polluting products from developing countries, the improvements experienced by the United States would not be replicable indefinitely on a global scale, because the poorest countries will never have even poorer countries from which to import their polluting products. However, if the cleanup has been the result of technology, that may well be replicable indefinitely, and may even be replicable more easily if there are economies of scale or learning-by-doing in abating pollution. 
To be clear, manufacturing is not the only source of pollution in the United States. It accounts for less than 25 percent of the most common air pollutants (U.S. EPA 2000). Nevertheless, manufacturing does account for a large share of the rhetoric in the debate about the economic consequences of environmental regulations, the changes over time in the structure of the U.S. economy, and the effect of international trade on U.S. production workers and other countries' environments. Other major polluting sectors, such as electric utilities and transportation, are not subject to concerns about pollution havens or industrial flight, which is why I focus on manufacturing here.

In Part 1, I use data from the U.S. Environmental Protection Agency (EPA) to determine how much of the cleanup of U.S. manufacturing comes from changes in technology versus changes in the mix of industries. Because the EPA data report emissions back to 1970 for only four common air pollutants, this first part focuses on air pollution. I show that for the typical air pollutant, the cleanup from technology is at least as large as the cleanup from compositional change, and for some it is more than two times as large. The pace of that technological progress, however, has been slowing over time. Even though this type of decomposition analysis has deep roots in economics, going back at least to Leontief (1970), to my knowledge this is the first paper to divide pollution changes into its components in this way, or to demonstrate the technological slowdown. ${ }^{1}$

In Part 2, I address whether the decline in U.S. pollution that results from increased imports is sufficiently large to explain the decline in pollution arising from the change in the composition of U.S. industries. Because this part does not require emissions data back to the 1970s, I expand the analysis to include 9 different air, water, and toxic pollutants. The basic approach was outlined by Koo (1974) and implemented in part by Khan (2003), Cole (2004), Ederington et al. (2004), and Gamper-Rabindran (2006). All this previous research finds that increases in imports of polluting goods cannot explain

\footnotetext{
${ }^{1}$ See Ang (1999), Rose (1999) and Metcalf (2007) for decomposition analyses of energy use and pollution. Most such analyses fall into one of two categories: (1) index decomposition analysis (IDA), which uses industry-level data; and (2) structural decomposition analysis (SDA), which combines industry-level data with input-output tables. In this paper, I use elements from both approaches, relying on IDA for Part 1, where input-output tables are unnecessary, and then adding the input-output tables in Part 2 to study changes caused by imports, but without allowing the input-output requirements coefficients to change annually. See also Pasurka (2003) for an update and an application using two-digit Standard Industrial Classification (SIC) codes and $\mathrm{SO}_{2}$ pollution.
} 
the composition shift of U.S. manufacturing toward cleaner goods. By ignoring the pollution caused by production of the intermediate inputs to imports, however, these papers all understate the degree to which those imports have displaced pollution in the United States.

To account for intermediate inputs to imports, in Part 2 I use EPA data along with U.S. Bureau of Economic Analysis (BEA) input-output tables to construct total emissions intensities for each U.S. manufacturing industry in 1997, including the pollution caused by each industry's intermediate inputs. I show that even after accounting for intermediate inputs, the composition of imports to the United States has shifted towards cleaner goods, and that increases in international trade can account for at most only half of the pollution reductions from the changing composition of U.S. manufacturing. Foreign pollution havens have had a relatively small role in the composition shift of U.S. manufacturing away from polluting goods, and that composition shift in turn has had a small role in the overall cleanup of U.S. manufacturing. Technology has played by far the most important role in cleaning up U.S. manufacturing pollution.

\section{Part 1: Technology - An Indirect Assessment of the Technique Effect}

Between 1972 and 2002, total air pollution from U.S. manufacturing declined by approximately 60 percent. In this part of the paper, I show that changing production techniques account for the largest share of this cleanup, but that this share has been declining over time.

\section{Scale, Composition, and Technique in Theory}

Environmental economists now have a convention for thinking about changes in total pollution as coming from three sources: the overall size of the economy ("scale"), the mix of sectors comprising the economy ("composition"), and the technologies employed in production and abatement ("technique"). ${ }^{2}$ Mathematically, the total amount of pollution from manufacturing, $(P)$, can be written as the sum of pollution from each of its component industries, $\left(p_{i}\right)$. This in turn can be written as the total value shipped from manufacturing, $(V)$, multiplied by the sum of each industry's share of total output, $\left(\theta_{i}=\right.$

\footnotetext{
2 See, for example, Grossman and Krueger (1993) or Copeland and Taylor (2005).
} 
$\left.v_{i} / V\right)$, times an emissions coefficient that reflects the amount of pollution per dollar of value shipped in that industry, $\left(z_{i}=p_{i} / v_{i}\right)$.

$$
P=\sum_{i} p_{i}=\sum_{i} v_{i} z_{i}=V \sum_{i} \theta_{i} z_{i}
$$

Or, in vector notation

$$
P=V \boldsymbol{\theta}^{\prime} \mathbf{z}
$$

where $P$ is a scalar representing the total pollution from manufacturing, and $\boldsymbol{\theta}$ and $\mathbf{z}$ are $n \times 1$ vectors containing the market shares of each of the $n$ industries and their pollution intensities, respectively. Totally differentiating equation (2) yields 3

$$
d P=\boldsymbol{\theta}^{\prime} \mathbf{z} d V+V \mathbf{z}^{\prime} d \boldsymbol{\theta}+V \boldsymbol{\theta}^{\prime} d \mathbf{z}
$$

The first term in equation (3) is the scale effect, which explains what happens to total pollution as the overall size of the manufacturing sector increases, holding the composition of industries and their pollution intensities fixed. The second term is the composition effect, which accounts for the changing mix of industries, holding their scale and pollution intensities constant. And the third term is the technique effect, which captures changes in pollution intensities, holding the scale and composition of manufacturing fixed. ${ }^{4}$

Data on total pollution, $(P)$, are taken from the National Emissions Inventory (NEI). The NEI is the U.S. EPA's clearinghouse for the wide variety of pollution data compiled by states and industries. It includes point, mobile, and area sources of pollution, including individual facility-level data for large point sources. The NEI reports emissions of four common air pollutants (known as "criteria" pollutants) back to 1970: $\mathrm{SO}_{2}, \mathrm{NO}_{\mathrm{x}}$, carbon monoxide $(\mathrm{CO})$, and volatile organic compounds (VOCs; a precursor to ozone, or

\footnotetext{
${ }^{3}$ Equation (3) assumes no interaaction terms - that changing the scale of manufacturing does not affect the pollution intensities for example. Or, equivalently, we can think of equation (3) as assuming that all of those interaction terms are combined into what I am calling technology, the third term which will just be a remainder after accounting for the first and second terms.

${ }^{4}$ Note that this technique effect could result from movement along a production possibility frontier (using a different mix of inputs within known production technologies), or a shift outward in a production possibility frontier (inventing new technologies). See Fare et al. (1989 and 2001).
} 
"smog"). To be consistent with the international trade data used in Part 2 below, I limit the analysis here to the period from 1972 to 2001.

Unfortunately, the NEI does not simply report the amount emitted by manufacturing alone. Instead, its emissions data are organized by "activity" (such as fuel combustion and transportation, among others). Table 1 describes the 14 categories of activities in the NEI. Those marked with an asterisk in the table are included here as an approximation of manufacturing emissions.

For data on total manufacturing output and the output of each industry ( $V$ and $v_{i}$ ), I use the manufacturing productivity database (NBER-CES; Bartelsman and Gray 1996). These are derived from the Annual Survey of Manufactures conducted by the U.S. Census Bureau.

Data on pollution intensities, $(\mathbf{z})$, are the final element. For these, I rely on the U.S. EPA's Trade and Environmental Assessment Model (TEAM), which has as its core a list of emissions intensities by six-digit North American Industry Classification System (NAICS) codes. These data were assembled by the U.S. EPA and Abt Associates (2004) to assess the environmental effect of economic changes, such as those that might arise from international trade agreements. TEAM uses the raw inputs to the $1997 \mathrm{NEI}$, first matching emissions to individual facilities and then aggregating across the six-digit NAICS codes to which those facilities belong. TEAM can be used to generate emissions factors (environmental consequences per dollar of output) for 1,099 six-digit NAICS industry codes, and for more than 1,000 different environmental outcomes, including air pollutants, individual toxic chemicals, hazardous waste, and land use. ${ }^{5}$ Here I focus on the 473 six-digit NAICS codes that comprise the manufacturing sector and on the four criteria air pollutants reported by the NEI consistently since 1970.

Estimating how much of the pollution reduction over the past 30 years can be attributed to each of the three effects in equation (3) requires annual data on total pollution, $(P)$, total output, $(V)$, and each industry's contribution to output, $\left(\theta_{i}\right)$. The one element of equation (3) that is not available by year is $\mathbf{z}$, each industry's emissions

\footnotetext{
${ }^{5}$ TEAM also disaggregates these emissions factors geographically (by U.S. county), although I am relying on national averages for this study.
} 
intensity. I have data on $\mathbf{z}$ for only one year, 1997, and so I calculate the first and second terms in equation (3) and calculate the third term as the remainder.

At this point, it is worth raising a few conceptual data issues - the NEI approximation of manufacturing pollution, outsourcing electricity generation, changing industry definitions, and changing relative product prices.

\section{The NEI Manufacturing Approximation}

The NEI categorizes pollution by "activity code", as listed in Table 1, and no combination of those codes exactly matches the manufacturing sector. The best I can do is to approximate total manufacturing pollution using the five activity codes marked with asterisks in Table 1. This means that the definition of "manufacturing" in the TEAM data (used to construct $\mathbf{z}$ ) will differ from the definition in the NEI data (used to construct P). Fortunately, all I am really concerned about is explaining pollution changes in percentage terms (with units being irrelevant to the decomposition). For this reason, any mismatch between the TEAM and NEI data will not be a problem as long as the ratio of the NEI approximation to the true pollution from manufacturing remains constant over time. If true manufacturing pollution grows relative to this NEI approximation, I will be increasingly understating pollution from manufacturing and exaggerating the role of technology in abating pollution. More likely, if true manufacturing pollution shrinks relative to the NEI approximation, I will be increasingly overstating manufacturing pollution and understating the role of technology.

For some recent years (1990 and the period from 1996 to 2001), the U.S. EPA documented pollution by two-digit Standard Industrial Classification (SIC) codes, making it possible to see whether the ratio of true manufacturing pollution to the NEI approximation changed over time, if only for a short portion of the entire three-decade time span. Table 2 presents this ratio, the sum of pollution from all manufacturing SIC codes (20 through 39 ), divided by the total manufacturing pollution from the NEI approximated by the five starred activity codes in Table 1 . The ratios remain remarkably stable. None display marked upward trends. If anything, the overall trend is downward, suggesting that the NEI approximation may increasingly overstate pollution from manufacturing, If so, my decomposition analysis will understate the role of technology in abating that pollution. 


\section{Outsourcing Electricity Generation}

A second potential concern about this analysis is that much of the pollution being studied is emitted as a byproduct of energy generation. If over time manufacturers increasingly purchase electricity from utilities, rather than generating power themselves, pollution may simply be moving from the manufacturing sector to the utility sector. Any cleanup we perceive in manufacturing may be the spurious result of outsourcing electricity generation.

To see whether manufacturers are increasingly purchasing electricity from offsite generators, I examined data from the Manufacturing Energy Consumption Survey (MECS), which has been conducted every third or fourth year since 1985. Net purchases of electricity by manufacturers has remained constant at between 22 and 24 percent over the past two decades (see Table 3). While I cannot say for sure that increased outsourcing of electricity generation does not explain some of the declines in manufacturing pollution prior to 1985, outsourcing has not been responsible for the declines since 1985.

\section{Changing Industry Definitions}

The U.S. manufacturing data (and the international trade data used in Part 2) are organized by four-digit SIC codes that were defined in 1987. The TEAM data use the NAICS codes as defined in 1997. Each is a hierarchical numerical classification of industries, with similar industries grouped into separate classifications.

To match the SIC and NAICS industry classifications, I rely on a Census Bureau publication of the 1997 industry-level aggregates using both the SIC and NAICS classifications (U.S. Census Bureau 2000). ${ }^{6}$ From these 1997 data I constructed a concordance, or "crosswalk," between the 1987 SIC codes and the 1997 NAICS codes. The concordance reports the fraction of the output of each four-digit SIC code that is attributable to each six-digit NAICS code and vice versa. ${ }^{7}$

\footnotetext{
${ }^{6}$ Electronic versions of this publication can be found at www.census.gov/epcd/ec97brdg.

${ }^{7}$ For some industries, the Census Bureau withholds the value shipped to avoid disclosing confidential business information. In those cases the share of establishments serves as a proxy for value shipped. I assume that the share of establishments equals the share of value shipped for industries where value shipped is undisclosed. Within industry groups (the NAICS four-digit codes), I then subtract the sum of value shipped for the reporting industries to obtain the residual undisclosed amount. Next, I apply the proportions calculated from establishment numbers to the residual undisclosed amount to estimate the value shipped for each undisclosed industry.
} 
The final data set includes only those observations that are defined as manufacturing in both data sets: SIC codes 2011 through 3999 and NAICS codes 31111 through 339999. This eliminates cases where the industry redefinition changed whether or not an industry was included in the manufacturing sector. It contains crosswalks between 453 four-digit SIC codes in 1987 and 469 six-digit NAICS codes in 1997. Of these, the SIC and NAICS codes matched perfectly in 229 cases, where the reclassification merely relabeled the industry.

\section{Changing Relative Product Prices}

Comparisons across three decades necessitate adjusting for price inflation, which would be a simple task if prices of all goods changed proportionately. But in some industries, prices rose faster than the average for the manufacturing sector. Petroleum prices, for example, grew faster than the producer price index (PPI) from 1972 to 2001 (508 percent for petroleum refineries [SIC 2911] compared to 237 percent for the PPI). Manufacturing expensive fuel, though, does not pollute more than manufacturing cheap fuel. If we divide each industry's output by the overall PPI, and then multiply by its emissions coefficient to get predicted pollution, we will overstate the growth of pollution from petroleum and exaggerate the role of technology in abating that pollution. This line of reasoning would suggest using industry-specific price deflators.

On the other hand, many industries have seen spectacular falls in their relative prices resulting from changes in the natures of their underlying products. The PPI for computers (SIC 3571) fell 99 percent from 1972 to 2001. If we take that literally, and adjust each industry's value shipped by an industry-specific measure of inflation, we would have to multiply the value of computer production by 100 . But manufacturing computers with faster processors does not necessarily pollute more than manufacturing slow computers. If we divide each industry's output by an industry-specific price index, then multiply by its emissions coefficient, we will vastly overstate the growth of pollution from computer manufacturing. Because high-tech industries that have experienced these types of price deflations tend to be less polluting, using their industry-specific price indices will overstate the "green" shift in the composition of U.S. manufacturing output 
toward clean products and understate the role of technology. This line of reasoning would suggest using an economy-wide price deflator such as the PPI. ${ }^{8}$

In the energy industries, prices rose because of factors unrelated to the nature of the product. Deflating output using the PPI, then, would overstate the growth of energy industries. Since energy industries are relatively pollution intensive, using the PPI would exaggerate the predicted amount of pollution based on the scale and composition of manufacturing, in turn exaggerating the technique effect. Notably, this method would also exaggerate the growth of energy-intensive industries from 1970 through the mid1980 s - when energy prices rose fastest - and understate their growth after 1985. This would lead to overstating the technique effect before the mid-1980s and understating it thereafter. The end result would overstate the slowdown of technology's contribution to pollution abatement.

In the computer and electronic industries, the nature of the products changed, and BEA economists have calculated an implicit price decline. If we adjust nominal computer sales using the BEA index for computers, we inflate that relatively clean industry's output, overstate its share in predicted overall manufacturing pollution, and understate the technique effect.

To be complete, I have calculated results using both the PPI and industry-specific price deflators, but I focus on the industry-specific analysis, keeping in mind throughout that this will likely overstate the composition effect relative to the technique effect. Given that the bottom-line results of this first part of the analysis are that (1) the technique effect dominates and (2) technique's dominance has declined, using the industry-specific deflators represents the more conservative of the two approaches.

\section{Scale, Composition, and Technique in Practice}

Figure 1 illustrates the analysis for the sulfur dioxide (SO2) emissions. (Figures for the other pollutants look similar.) The top line - line number 1 - simply reports the total value of manufacturing shipments, scaled so that the 1972 value equals 100 . If the mix of industries making up the manufacturing sector remained constant $(\mathrm{d} \theta=0)$, and the

\footnotetext{
8 Some analysts have even suggested that computer-related industries should use a constant deflator (Meade 2000).
} 
techniques of production remained constant $(\mathrm{d} z=0)$, this top line would represent how emissions would have changed over time. The manufacturing sector grew by 71 percent over this period. This is the scale effect. ${ }^{9}$

The bottom line - line 2 - plots SO2 emissions by the manufacturing sector, as reported by the NEI and scaled so that 1972 emissions equal 100. Emissions drop steadily, and 2001 SO2 emissions are 66 percent below their 1972 levels. This represents the combined scale, composition, and technique effects, or $(\mathrm{d} P)$ in equation (3).

The middle line in Figure 1 - line 3 - is the result of multiplying each industry's value of shipments in each year $\left(v_{i t}\right)$ by the TEAM emissions coefficient for SO2 in 1997 $\left(z_{i}\right)$ and aggregating across industries. It represents what $\mathrm{SO} 2$ emissions would be in each year if each separate manufacturing industry produced its concurrent output, but used the production technique that generated the same amount of SO2 per dollar of output that it did in 1997. This combines the scale and composition effects, which grew by 19 percent from 1972 to 2001.

These three numbers (scale up 71 percent, SO2 down 66 percent, scale and composition up 19 percent) are listed in the first three columns of Table 4. Columns (4) through (6) contain the share of the total cleanup that can be attributed, respectively, to the scale, composition, and technique effects. Manufacturing grew by 71 percent and SO2 emissions fell 66 percent. Therefore the scale effect more than completely offsets the decline in pollution (or minus 107) percent of the decline SO2 in emissions can be attributed to changes in the scale of manufacturing).

The composition effect is simply the difference between lines (1) and (3) in Figure 1. Scale added 71 percent to SO2 emissions and scale and composition together added 19 percent. As a result, the composition effect alone amounts to a 52 percent drop in SO2 emissions (relative to the 1972 baseline). This reduction accounts for 79 percent of the total emissions decline of 66 percent.

Finally, the technique effect is simply the difference between lines (2) and (3) in Figure 1. Scale, composition, and technique together result in an SO2 emissions

\footnotetext{
${ }^{9}$ This calculation is based on the summation of the value of shipments of six-digit NAICS codes, where each industry's value shipped is indexed using an industry-specific price deflator. If instead I aggregate across industries before applying an economy-wide PPI, manufacturing output grows by 55 percent.
} 
reduction of 66 percent. Scale and composition alone result in an increase of 19 percent. Therefore the technique effect alone must amount to a 85 percent drop in emissions, or 128 percent of the total emissions decline of 66 percent. Changes in technique from 1972 to 2001 have reduced pollution from the 2001 manufacturing sector by more than the total amount of pollution the sector emitted in 1972.

As a summary statistic for these calculations, Column (7) in Table 4 reports the ratio of the technique effect to the composition effect, 1.62. This means that the SO2 emissions reductions resulting from changing production technologies are more than 1.5 times as large as the emissions reductions resulting from the changing mix of industries that comprise manufacturing.

Table 4 also presents this same calculation for the other three criteria air pollutants individually. Even though we can see differences based on the patterns of pollution emissions and growth across industries, the overall result is consistent. In each case, the technique effect (Column (6)) accounts for more than 100 percent of the cleanup. For VOCs, the composition effect is small, and as a consequence the ratio of technique to composition is large (2.71). But in absolute terms the technique effect in Column (6) is approximately the same size as for the other pollutants. The bottom row of Table 4 contains the same set of calculations for the unweighted sum of all four pollutants. Overall, changing technology reduced air pollution from manufacturing by 1.44 times as much as changing the composition of the manufacturing sector.

Table 5 presents the ratio of technique to composition for some alternative versions of these calculations. Column (1) contains the baseline for comparison, repeating Column (7) of Table 4. In Column (2) of Table 5, I conducted the same exercise, but used the PPI to deflate industry output instead of using industry-specific price deflators. As expected, this greatly increases the estimate of technique relative to composition, mostly by exaggerating the growth of pollution from energy-intensive industries.

In column (3) I address the opposite concern, that the industry-specific index for computers overstates their importance in the cleanup of manufacturing. I conduct the entire analysis without the eight SIC codes where the industry-specific price index falls 
between 1972 and 2001. ${ }^{10}$ Deflating output from those eight industries suggests their output grew by more than as measured by nominal prices, and if they do not pollute much may overstate their role in the composition effect on pollution. As a consequence, dropping these eight industries results in a large estimate of the technique effect. The ratios of technique to composition effect in column (3) suggest the corresponding calculations in column (1) should be interpreted as lower bounds on the role of technology. Those baseline numbers inflate the role of composition change by exaggerating the shift towards relatively non-polluting high-tech industries. The baseline calculation in column (1) thus represents a conservative estimate of the role of technology in reducing pollution, because it uses industry-specific price deflators which exaggerate the shift towards relatively clean computers and electronics industries.

Columns (4) and (5) describe the change in this ratio over time. Looking back at Figure 1, the technique effect is the difference between the bottom line (scale, composition, and technique) and the middle line (scale and composition). The gap appears to grow quickly during the first decade or so and then slow down, suggesting that the technique effect has diminished in importance over time. To document this, Table 5 reports the ratios of technique to composition for two separate time periods: 1972-1985 and 1985-2001. In each case, the ratio of technique to composition is smaller during later years. Technique appears to have played a larger role than composition in the cleanup of U.S. manufacturing, but the ratio falls over time.

All four of the air pollutants show a marked decline in the technique effect over the three decades since the 1970s. There may be several reasons for this. First, marginal abatement costs could be increasing, and all of the least expensive abatement technologies might have been employed in the response to the 1970 and 1977 Clean Air Acts. ${ }^{11}$ However, it seems equally likely that there are increasing marginal costs

\footnotetext{
10 These are electronic computers (3571), computer storage devices (3572), computer terminals (3575), computer equipment n.e.c. (3577), calculating and accounting machines (3578), household audio and video equipment (3651), semiconductors (3674), and magnetic and optical media (3695).

${ }^{11}$ Cost-minimizing polluters will employ abatement technologies in the order of increasing marginal cost, which means that as more is done, abatement becomes more costly. If polluters were mandated to reduce pollution, but left on their own to choose the method (output reduction, international outsourcing, or technological abatement), we might expect to see the pattern depicted in Table 4. Of course, polluters were not free to choose because technologies were mandated by the 1970, 1977, and 1990 Clean Air Acts. Those laws, however, may reflect the underlying realities of increasing marginal cost and mandate successively smaller increments in abatement.
} 
associated with altering the composition of U.S. manufacturing or relocating industries abroad. Some industries have inelastic demand and are immobile, and their share of output is unlikely to decline. Others have elastic demand or are mobile, and U.S. production should decline in the face of increasing costs. Whether increasing marginal costs of technological abatement are larger or smaller than the increasing marginal costs of compositional change is an open question. It is not obvious a priori that the ratio of technique to composition effects will necessarily fall over time.

A second explanation for the falling ratio of technique to composition is that regulators may have demanded successively smaller increases in abatement technology. If there is a trend away from U.S. production of polluting goods that is unrelated to regulations, that effect will come to dominate over time as technological advances shrink.

Third, and perhaps most likely, the diminishing importance of technology in abating polluting may be due to the fact that energy prices increased sharply during the 1970s and early 1980s, and decreased thereafter. High energy costs gave manufacturers incentives to increase energy efficiency, which also reduced pollution. The high energy costs were experienced world-wide, and could not be avoided by relocating overseas. Hence in the 1970s and early 1980s we see technique dominating composition. Once energy costs start to fall in the mid-1980s, energy efficiency improvements slowed down, and composition changes took on greater importance.

Before drawing general conclusions about the analysis so far in Part 1, one important caveat deserves mention: intra-industry composition.

\section{One final caveat: Intra-industry composition}

The analyses in tables 4 and 5 rely on a decomposition of the U.S. manufacturing sector into 469 six-digit NAICS industry codes. These codes represent a relatively fine categorization of industries. Twenty-five different six-digit NAICS codes comprise the primary metals industries, ranging from iron foundries to rolled steel shape manufacturers. Eighteen codes make up paper manufacturing, ranging from pulp mills to envelope manufacturers. Despite the level of disaggregation, a concern remains - that heterogeneity within six-digit NAICS codes may be driving what I describe here as a technique effect. If six-digit NAICS industries contain subindustries of varying pollution intensity, and the composition of individual industries has shifted toward less-polluting subindustries over time, some of what I have described as a technique effect may actually be another form of composition effect, at a level of disaggregation too fine to see with the 
six-digit NAICS classifications. However, composition changes within NAICS codes would have to be implausibly large relative to those across NAICS codes to overturn the basic result of this analysis - that technology accounts for more pollution reduction than composition change.

\section{Part 1 Conclusion: The Role of Technology in Pollution Abatement}

Even being cautious about the role of relative price indices and the possibility of intra-industry composition effects, the implications of the simple decomposition here are stark. Air pollution from manufacturing has declined significantly in the United States despite increases in manufactured output. Most of this improvement seems to arise from changes in the way goods are produced (technique), rather than the types of goods produced (composition), although the role of technique may be waning.

A substantial composition effect does remain, however. Changes in the mix of industries have reduced air pollution from manufacturing by as much as 36 to 60 percent relative to the amount in $1972 .{ }^{12}$ And that composition effect grows in importance as the technique effect fades. This change in manufacturing composition could itself come from one of two sources - changes in consumption or changes in net imports. If the change comes from imports, important concerns arise for the environment in the origin countries, especially the least developed countries. In the future, these countries will not be able to repeat U.S. success in abating pollution without even less-developed countries from which to import polluting goods. In Part 2, I ask explicitly how much of the pollution reductions from composition change can possibly be explained by the increase in net imports of pollution-intensive manufactured goods.

\section{Part 2: International Trade - An Input-Output Approach to Measuring Embodied Pollution}

Part 1 shows that although most of the pollution reduction from U.S. manufacturing has come from technology, a significant and growing part has also come from shifting over time toward production of less-polluting goods. A logical next question to ask is how much this green shift in U.S manufacturing can be explained by increasing imports of more-polluting goods. For comparison with Part 1, I continue using

12 This is the difference between Columns (2) and (3) in Table 4. 
the four pollutants studied earlier. But because I do not need emissions data back to 1972 for this part of the paper (I only need the industry-specific emissions coefficients (z) for one year), I expand the analysis to study 9 different air, water, and toxic pollutants.

A number of papers have examined this issue, but the standard approach has had several shortcomings. First, all the papers to date use the World Bank's 1987 Industrial Pollution Projection System (IPPS), which is now two decades old. ${ }^{13}$ If environmental regulations and technological progress have succeeded in reducing the pollution emitted per unit of output from the dirtiest industries, using the IPPS exaggerates the degree to which the change in the composition of the U.S. manufacturing sector has reduced pollution. ${ }^{14}$ Moreover, the IPPS index is based on pollution data from 1987 that have since been refined. For example, one input to the IPPS is the Toxics Release Inventory, for which 1987 was the first year of data collection, with low participation rates by industry. I use the TEAM data described in Part 1, which is based on emissions and output data from 1997. These more-recent data are less likely to exaggerate the green shift of U.S. manufacturing or imports.

More importantly, papers to date on this topic have focused only on the pollution content generated by each industry directly, ignoring the pollution generated by the manufacture of intermediate inputs to those industries. This is appropriate when documenting changes in U.S. manufacturing, where intermediate good production is counted separately. But for imports, where only the final good is observed, omitting pollution from intermediate goods can significantly understate the potential role of trade in the green shift of U.S. manufacturing. To address this factor content issue, I use the BEA's benchmark input-output tables for 1997, along with a Leontief-style input-output model to adjust the TEAM emissions content for the total pollution displaced by imports, including their intermediate inputs.

\footnotetext{
13 The IPPS is described in Hettige et al. (1995). Previous studies using the IPPS include Kahn (2003), Schatan (2003), Cole (2004), Ederington et al. (2004), and Gamper-Rabindran (2006).

14 This is essentially an environmental version of the standard Laspeyres-Paasche price index problem. Using an index (prices or pollution intensities) from earlier in the time beriod overstates the change (price inflation or the composition effect). Using an index from later in the time period overstates the change. Thus by using the 1997 TEAM data to measure pollution intensities, I overstate the relative cotribution of composition change to reducing pollution, and provide a conservative estimate of the importance of technolgy.
} 
I conduct two straightforward exercises. First, I show that despite the concerns of trade agreement opponents and antiglobalization protesters, the pollution content of imports to the United States has become cleaner over time, not dirtier, even accounting for pollution from intermediate inputs to imports. In fact, imports have been getting cleaner faster than domestic production. Second, in a simple thought experiment, I offset the effect of trade on U.S. manufacturing by adding all increases in imports over the past 30 years back into U.S. production, and subtracting all increases in exports. I compare the pollution that would have been generated by this hypothetical "no-trade-growth" U.S. manufacturing base to that generated by the actual U.S. manufacturing base. Despite enormous growth in the scale of imports, trade increases have not been large enough to account for the green shift of U.S. manufacturing. For most pollutants, increased trade is sufficient to explain no more than about half of the pollution reductions from the composition change of U.S. manufacturing.

\section{The Composition of Trade}

The concerns voiced about the relationship between pollution and trade have a common theme - that industries will relocate outside the United States to save on environmental compliance costs. If this has been happening, over time we should see relatively less manufacturing of highly polluting goods in the United States and relatively more net imports of those goods from overseas. Part 1 documented the green shift of U.S. manufacturing. Here, I apply a similar approach to imports.

Let $P^{M}$ be the amount of domestic pollution displaced by imports, by which I mean the amount of pollution that would have been emitted in the United States had those imported goods been produced domestically. $P^{M}$ can be written as the sum of the pollution displaced by each industry, $p_{i}{ }^{M}$, which in turn can be written as the total value of imports, $\left(V^{M}\right)$, times the sum of each industry's share in that total, $\left(\theta^{M}=v_{i}^{M} / V^{M}\right)$, times each industry's emissions per dollar of shipments in the United States, $\left(z_{i}=p_{i} / v_{i}\right)$.

$$
P^{M}=\sum_{i} p^{M}{ }_{i}=V^{M} \sum_{i} \theta^{M}{ }_{i} z_{i}
$$


This is a direct analog to equation (1), which applies to U.S. domestic production. Data on $V^{M}$ and $\theta^{M}$ come from the Center for International Data (Feenstra 1996, 1997), and have been translated from SIC codes to NAICS codes using the concordance described in Part $1 .{ }^{15}$ Note that $P^{M}$ does not tell us the amount of pollution occurring overseas as a consequence of producing goods for the United States, because other countries presumably have different emissions coefficients $(\mathbf{z})$. Rather, $P^{M}$ is the amount of pollution that would have been emitted in the United States had those imports been produced domestically.

How much of the green shift of U.S. manufacturing can be explained by the pollution displaced by imports, as measured by equation (4)? Figure 2 begins to illustrate the analysis for SO2 emissions. The top line in Figure 2 is an index $(1972=100)$ of real U.S. manufacturing imports, which grew 641 percent from 1972 to 2001 . This is analogous to the scale effect of manufacturing. If imported goods contain the same mix of industries as domestic production, we could say that the amount of U.S. pollution displaced by imports grew 641 percent.

Of course, the composition of imported goods has also been changing over time. Multiplying each industry's imports by its 1997 SO2 emissions coefficient and then aggregating across industries for each year generates the bottom line depicted in Figure 2. SO2 emissions displaced by imports would grow by 146 percent. Or, put differently, SO2 emissions displaced by imports were 67 percent lower than the pure scale effect of imports would predict. ${ }^{16}$ Column (2) of Table 6 contains these calculations of the composition effect of imports for nine individual pollutants. The composition effects range from 61 percent for VOCs to 82 percent for biological oxygen demand (BOD), a measure of water pollution. ${ }^{17}$

Column (1) of Table 6 contains these same calculations for the effects of scale and composition on U.S. pollution, using equation (1). These effects are much smaller

\footnotetext{
15 The Center for International Data at the University of California Davis (UCD) can be found at http://cid.econ.ucdavis.edu. The data run from 1972 to 2001.

16 This calculation is $(1+1.46) /(1+6.41)-1$.

${ }^{17}$ I could, in theory, apply this analysis to any of the more than 1,000 chemicals documented in the TEAM data. Here I use the criteria pollutants, for comparison with Part 1, along with two common measures of water pollution (BOD and total suspended solids [TSS]) and two aggregations of toxic chemicals (released to air and released to water).
} 
than the calculations for imports in Column (2). The changing composition of U.S. manufacturing reduced the benchmark four criteria air pollutants by 30 percent; the changing composition of imports (by this calculation) reduced the pollution displaced by those imports by 66 percent. This begins to suggest that imports have been shifting toward cleaner goods faster than domestically produced goods, and that increased trade may not account for (or even contribute to) the green shift of U.S. manufacturing. And here is where the previous literature stops.

There are two problems, however, with stopping at this point and merely pointing out that the composition effect as measured using the simple emissions coefficients tilts imports toward cleaner industries. First, the simple emissions coefficients neglect the intermediate inputs to those imports. Second, focusing solely on the composition effect ignores the fact that imports grew so much more in absolute terms than domestic production. I address each in order.

Recent prior work has ignored pollution from intermediate inputs. A simple example may help to explain the problem. Suppose that in an initial time period the United States produces automobiles. Each car requires one ton of steel as an input, and steel is entirely produced domestically. In the second time period, the United States imports one more car and produces one fewer. How much of the decline in U.S. pollution can be accounted for by the increase in imports? In the example, we can account for 100 percent by construction. But if we simply multiply the change in imports by the respective direct emissions coefficients (the calculation in equation (4) and Figure 2), we understate the pollution displaced by imports because there are no steel imports. The change in steel production occurs abroad and is embedded in the car. Using the direct emissions coefficients ignores the pollution generated by intermediate inputs to imports, and makes it appear as though import composition is shifting toward cleaner goods faster than it is in reality. The direct emissions coefficients therefore understate the amount of U.S. pollution reduction that is merely the consequence of increased imports.

To correct this, we need to account for not only the pollution embodied in the intermediate inputs to imports, but also the pollution embodied in the intermediate inputs to those intermediate inputs, and so on ad infinitum. (The steel used to make cars itself 
requires inputs that may produce pollution, and so on.) For this calculation, I rely on a basic Leontief input-output framework. ${ }^{18}$

Suppose that $x_{i}$ represents the total output of sector $i$, including intermediate inputs to other industries and final output to either consumption or export. The total dollar amount of good $i$ required directly in the production of one dollar's worth of good $j$ is $c_{i j}$. Final output is $y_{i}$. Total output, $\mathbf{x}$, which is a vector of $n$ outputs - one from each industry - is the sum of output used as intermediate goods and final output.

$$
\left[\begin{array}{c}
x_{1} \\
\vdots \\
x_{n}
\end{array}\right]=\left[\begin{array}{ccc}
c_{11} & \cdots & c_{1 n} \\
\vdots & \ddots & \vdots \\
c_{n 1} & \cdots & c_{n n}
\end{array}\right]\left[\begin{array}{c}
x_{1} \\
\vdots \\
x_{n}
\end{array}\right]+\left[\begin{array}{c}
y_{1} \\
\vdots \\
y_{n}
\end{array}\right]
$$

Or, in vector notation:

$$
\mathbf{x}=\mathbf{C x}+\mathbf{y}
$$

where $\mathbf{C}$ is an $n \times n$ matrix of direct requirements coefficients with elements $c_{i j}$ representing the dollar value of input industry $i$ needed to produce one dollar's worth of output industry $j$.

When we examine U.S. production, we are observing $\mathbf{x}$, the value of all shipments, including both intermediate inputs and final products. We can appropriately estimate pollution, then, by multiplying $\mathbf{x}$ by a vector of direct emissions coefficients $\mathbf{z}$, such as those from TEAM. But when we examine imports, we see only final product $\mathbf{y}$, without all of the intermediate production. In this case, we need a set of total pollution coefficients. These coefficients must embody all the pollution generated by all of the inputs to $\mathbf{y}$, all the inputs to those inputs, and so on. To calculate this, we can solve equation (6) for $\mathbf{x}$ to get

$$
\mathbf{x}=[\mathbf{I}-\mathbf{C}]^{-1} \mathbf{y}
$$

where $\mathbf{I}$ is the identity matrix. The matrix $\mathbf{T}=[\mathbf{I}-\mathbf{C}]^{-\mathbf{1}}$ is the Leontief total requirements matrix. Each element $t_{i j}$ contains the dollar amount of industry $i$ necessary to produce one dollar of output industry $j$, including the amount of $i$ used in all other industries that are used in $j$, as well as the amount of $i$ used in the inputs to those industries, and so forth.

18 See, for example, Miller and Blair (1985). 
The vector $\mathbf{x}$ represents the total amount of manufactured goods necessary to produce output $\mathbf{y}$. To generate the total pollution coefficients, I simply premultiply the Leontief total requirements matrix by the $\mathbf{z}$ vector from TEAM as follows:

$$
\tilde{\mathbf{z}}=\mathbf{z}^{\prime} \mathbf{T}=\mathbf{z}^{\prime}[\mathbf{I}-\mathbf{C}]^{-1}
$$

The only new piece of information we need to construct $\tilde{\mathbf{z}}$ is $\mathbf{C}$, the matrix of direct requirements coefficients. The BEA publishes an input-output table for the United States, and I use the 1997 version to create the matrix $\mathbf{C}$ for the manufacturing sector. The BEA tables are organized by commodity rather than industry, but for the manufacturing sector, commodity codes mostly map one to one into NAICS industry codes. For those that do not, I aggregate up to the level of five-digit NAICS codes, and, in 13 cases, to four-digit NAICS codes. The resulting $\mathbf{C}$ matrix is $344 \times 344$.

Using the total emissions coefficients, $\tilde{\mathbf{z}}$, in place of the direct emissions coefficients, $\mathbf{z}$, captures all of the pollution generated by intermediate goods, and does not understate displaced pollution. There is, however, a further complication. If the steel used in the production of automobiles in the United States is entirely imported, importing an automobile from abroad displaces no U.S. steel pollution, and the appropriate emissions coefficient is the direct one $(z)$. Suppose, however, that 10 percent of the steel used in U.S. automobile production is imported in the first period. If the U.S. imports one car in the second period, U.S. steel production declines by 0.9 tons and steel imports decline by 0.1 tons. Pollution in the United States declines by the amount emitted from manufacturing one automobile and 0.9 tons of steel.

The only way to solve this problem is to adjust the pollution coefficients to account for the imported fraction. We must multiply the direct requirements coefficients by the fractions of goods in each industry that are produced domestically. In other words, we need to replace the $\mathbf{C}$ matrix in the inverse Leontief calculation with $\operatorname{diag}(\mathbf{d}) \mathbf{C}$, where d is an $n \times 1$ vector whose elements are the share of each industry supplied by domestic production. ${ }^{19}$

19 The domestic share of supply is defined as 1 - imports/(domestic production + imports - exports). 


$$
\begin{aligned}
& \mathbf{z}^{*}=\mathbf{z}^{\prime}[\mathbf{I}-\operatorname{diag} \mathbf{( d ) C}]^{-1} \\
& {\left[\begin{array}{lll}
z_{1}^{*} & \cdots & z_{n}^{* *}
\end{array}\right]=\left[\begin{array}{lll}
z_{1} & \cdots & z_{n}
\end{array}\right]\left(\mathbf{I}-\left[\begin{array}{ccc}
d_{1} c_{11} & \cdots & d_{1} c_{1 n} \\
\vdots & \ddots & \vdots \\
d_{n} c_{n 1} & \cdots & d_{n} c_{n n}
\end{array}\right]\right)^{-1}}
\end{aligned}
$$

These emissions coefficients, $\mathbf{z}^{*}$, are total domestic requirements emissions coefficients. ${ }^{20}$

Figure 2 demonstrates the effect of this adjustment. The bottom line depicts the amount of U.S. pollution displaced by imports, using the direct emissions coefficients that fail to account for intermediate goods (z). The middle line uses the total domestic requirements emissions coefficients ( $\mathbf{z}^{*}$ in place of $\mathbf{z}$ ). Multiplying each industry's imports by its $\mathbf{z}_{i}{ }^{*}$, and then aggregating across industries for each year, shows us that SO2 emissions displaced by imports would grow by 385 percent. If we use $\mathbf{z}^{*}$ instead of $\mathbf{z}$, we see that emissions displaced by imports are 44 percent lower than the 641 percent increase that would have been predicted by the growth in the scale of imports alone.

Table 6 contains this calculation - the composition shift of imported goods using the total domestic emissions coefficient (Column 3) - along with similar calculations for each of nine individual pollutants. The numbers range from 28 percent for $\mathrm{CO}$ to 81 percent for BOD. In every case, the displaced pollution estimated using the total domestic requirements coefficients is larger than the estimate obtained using the direct requirements coefficients (because the coefficients are by definition larger). Consequently, the estimated green shift of imports is smaller.

U.S. imports are dominated by trade with other industrialized countries, but pollution haven worries focus on developing countries. To address this, column (4) of Table 6 presents the same calculation for imports from outside of the OECD. It turns out, however, that the green shift in imports from non-OECD countries toward cleaner goods is approximately as large as the green shift in imports in general, and typically much larger than the green shift in U.S. manufacturing.

Adjusting for factor content diminishes the previous result (that imports shifted toward cleaner goods faster than goods manufactured domestically), but does not

\footnotetext{
${ }^{20}$ Note that this assumes that the fraction of any input that is imported is the same, regardless of which industry uses it.
} 
eliminate it. Most of the import growth seems to have come from industries that were not pollution intensive in the United States, even after accounting for pollution from intermediate inputs. Even though previous studies - in which analysts used direct requirements coefficients - got the magnitude wrong, the basic finding remains valid. The U.S. manufacturing sector has shifted away from polluting goods, and imports have shifted even further away from polluting goods. The green shift of U.S. manufacturing has not been accompanied by a corresponding "brown" shift in imports to the United States. Instead, imports have been shifting toward cleaner goods faster than those produced domestically.

Results like these have been interpreted as evidence that U.S. environmental policies are not pushing U.S. polluting manufacturers overseas, but that conclusion does not necessarily follow. We do not know what the composition of imports would have been without changes in U.S. environmental regulations. Perhaps imports would have shifted toward less-polluting goods even faster. The best we can do with these data is ask whether the overall size of import growth is sufficient to account for the pollution reductions resulting from the green shift of U.S. manufacturing. If import growth is small or composed of clean industries (with clean intermediate inputs), the composition-related pollution reductions in the United States cannot possibly be explained by international trade.

Whether international trade increases have been sufficient to account for the green shift of U.S. manufacturing depends on both the composition and scale of imports, and these effects work in opposite directions. Although imports became 28 to 81 percent cleaner from 1972 to 2001, those imports increased by more than five times. This might leave ample room for imports to replace pollution generated during domestic production because the overall pollution content of imports (counting both the composition and scale) has increased.

\section{The Pollution Content (Scale and Composition) of Trade}

Figure 1 illustrates the last step in this analysis, explaining the fraction of U.S. emissions reduction that can be explained by changes in the combined scale and composition of imports. Recall that the gap between lines (1) and (3) depicts the green shift in U.S. manufacturing away from pollution-intensive goods. How much of this shift can be explained by increased imports? If we multiply each industry's net imports (imports minus exports) by the relevant total domestic requirements pollution 
coefficients, $\left(z_{i}^{*}\right)$, we obtain an estimate of the amount of U.S. pollution displaced by net imports. To show the change over time, use the difference between each year's net imports and net imports in 1972. This series is plotted as line (4) in Figure 1. Holding technology fixed as of 1997, this line represents what air pollution from manufacturing would have been if every bit of increased net imports since 1972 had instead been manufactured in the United States. As shown in the figure, adding back into U.S. emissions the amount displaced by imports (using the total emissions factors that account for pollution from intermediate goods) accounts for roughly half of the green shift of U.S. manufacturing. ${ }^{21}$

I recognize, of course, that this "no-net-trade-growth" scenario represents an extremely unlikely partial-equilibrium thought experiment. Had there been no net trade growth, surely the mix of goods consumed by the U.S. economy would have been much different. In no sense does the "without net imports" line in Figure 1 represent what the pollution content of U.S. manufacturing actually would have been absent trade growth. Instead, I think of the no-net-trade growth scenario as an accounting exercise - asking what fraction of the composition-related cleanup of U.S. manufacturing can be matched to increased imports of pollution-intensive products, not what pollution in the U.S. would have been absent the ability to import those products. In fact, if the U.S. imports pollution-intensive goods because they are less expensive when produced overseas, in the absence of trade growth the United States would likely consume and produce fewer pollution intensive goods, changing the baseline (pollution) and the overall scale (manufacturing output).

Table 7 summarizes this calculation. Adding back pollution displaced by net imports and accounting for intermediate goods accounts for 53 percent of this green shift for SO2 pollution (column (2)). Column (2) of Table 7 contains this same no-tradegrowth thought experiment for each of nine individual pollutants. For each of the pollutants except $\mathrm{CO}$, the net pollution embodied in the increased trade accounts for no more than about half of the green shift of U.S. manufacturing. For CO, trade accounts for 99 percent of the change. For BOD, exports of pollution-intensive goods grew enough

\footnotetext{
${ }^{21}$ Note that this no-trade-growth scenario exaggerates the role of trade, because it holds imports constant at their 1972 levels in real terms, which means that imports' share of manufacturing would decline over time. An intermediate case would hold the import growth rate equal to the growth of U.S. manufacturing.
} 
that the net effect of trade makes the U.S. industrial composition more pollution intensive, rather than less. ${ }^{22}$

Table 7 contains two other sets of calculations for comparison. Column (1) conducts the analysis using the direct requirement coefficients, failing to account for the pollution content of intermediate inputs to imports. The amount of the green shift of U.S. manufacturing explained by trade growth is much smaller ( 5 percent rather than 53 percent for SO2), but of course this understates the pollution content of imports by ignoring intermediate inputs. More significantly, Column (3) conducts the analysis for trade with non-OECD countries, which are of most concern to those worried about pollution havens. For most pollutants, trade growth with these non-OECD countries appears to account for only about one-quarter of the green shift of U.S. manufacturing.

\section{Displaced Pollution and the Pollution Havens Hypothesis}

These analyses demonstrate that the increase in the pollution content of imported goods is typically insufficient to explain the decline in U.S. manufacturing pollution resulting from the changing composition of U.S. industries. When we import a product, the pollution from its manufacture occurs abroad, not in the United States. I have focused here on the resulting decline in U.S. pollution, not the increase in overseas pollution. The results do not tell us what has happened to the environment in countries from which the United States imports goods, only what pollution in the United States would have been had those goods been produced at home - what I have called "displaced" pollution.

Furthermore, the analysis here implies no causality. I have not asked why the U.S. composition changed nor why imports increased. I have only attempted to show that the scale of imports is insufficient to account for the green shift of U.S. manufacturing, even including the pollution caused by intermediate inputs to imports.

\footnotetext{
22 These outliers are explained by a relatively small number of industries. Each industry's effect on the total depends on three items - the size of its imports and exports, the change in its imports and exports, and its emissions coefficient $\left(z_{i}^{*}\right)$. For CO, automobile imports alone grew by enough to displace 14 percent of U.S. CO emissions in 1972. Adding those imports back into U.S. production explains a large fraction of the decline in U.S. CO emissions. For BOD, pulp and paper exports alone grew enough to increase U.S. emissions by 27 percent. Subtracting those exports would have made the U.S. manufacturing sector significantly cleaner. No other industry-pollutant combination comes close to these two in terms of explaining the results in Table 6.
} 
A large body of literature does address these causal relationships. In particular, analysts have tried to assess the degree to which increasing environmental regulations in the United States have caused either the green shift or the increase in imports. The results of the analysis in this paper have no bearing on that literature. My finding that the composition of imports has been shifting toward clean goods faster than the composition of goods produced domestically does not mean that there is no pollution haven effect. Perhaps the green shift of imports would have been larger and the green shift of U.S. manufacturing smaller in the absence of U.S. environmental laws. The finding that the pollution content of imports is sufficient to offset only about half of the pollution changes resulting from the scale and composition of U.S. manufacturing does not mean that these changes were themselves caused by U.S. environmental laws. The changes in industry composition and imports are the result of many concurrent trends in addition to environmental costs, such as changes in labor, energy, shipping, and tariff costs, among others. Sorting out which costs drive changes in U.S. industrial composition and imports is a job for another paper. This paper merely documents that fact that the growth and composition of imports to the United States is sufficient to explain at most about half of the pollution reductions achieved from producing a cleaner mix of goods at home.

\section{Conclusion}

Separating the decline in manufacturing emissions into its three components (scale, composition, and technique) is important for several reasons. Most U.S. environmental regulations have been designed explicitly to affect production technologies, not to depress manufacturing or alter the mix of goods manufactured. And most measures of the costs of environmental regulations focus on easily measured costs of abatement technologies, not the diminished consumer or producer surplus from reduced or relocated production. If pollution reductions result from changes in the overall scale or composition of U.S. manufacturing, there could potentially be adverse consequences. Environmental improvements could then be said to have imposed large, unmeasured economic costs; to have imposed large changes in goods we consume; or to have shifted pollution from the United States to other countries. Furthermore, none of these changes would be replicable by all countries indefinitely. If the pollution reductions come from technological progress, however, there is nothing suggesting that the trend cannot continue indefinitely and be repeated around the world. 
The good news, then, is that most of the pollution reduction over the past 30 years has come from changes in technology, rather than from changes in imports or changes in the types of goods produced domestically. Criteria air pollutants collectively declined 58 percent from 1972 to 2001, despite a 71 percent increase in manufacturing output. The cleanup was accomplished by changing the mix of goods produced and by altering the technologies used to produce those goods. For a typical pollutant, technology accounts for a large majority of the cleanup. Moreover, although some of the improvement is due to the changing composition of industries, that change cannot be explained by increases in imports. For the typical pollutant, increased international trade explains at most half of the pollution reductions from composition changes in U.S. manufacturing. Those composition changes in turn explain less than half of the overall reduction in U.S. manufacturing pollution.

Together these findings suggest that the environmental concerns of antiglobalization protesters have been overblown, and that the pollution reduction achieved by U.S. manufacturing will replicable by other countries in the future. Most of the environmental improvements in the United States have come from technology, not from relocating polluting industries overseas. That good news must be tempered somewhat by the fact that the role of technology appears to be shrinking, making composition changes increasingly important to pollution reduction. 


\section{References}

Abt Associates, Inc. 2004. "Trade and Environmental Assessment Model: Model Description." Prepared for U.S. Environmental Protection Agency (EPA), National Center for Environmental Economics. Cambridge, MA: Abt Associates.

Ang, B.W. 1999. "Decomposition Methodology in Energy Demand and Environmental Analysis." Pages 1146-1163 in Handbook of Environmental and Resource Economics. Edited by J. van den Bergh. Northampton, MA: Edward Elgar.

Ang, B.W., and F.Q. Zhang. 2000. "A Survey of Index Decomposition Analysis in Energy and Environmental Studies." Energy - The International Journal. 25(1): 1149-176.

Bartelsman, E.J., and W. Gray. 1996. "The NBER Manufacturing Productivity Database." NBER Technical Working Paper No. 205. Cambridge, MA: National Bureau of Economic Research (NBER).

Brunnermeier, S., and A. Levinson. 2004. "Examining the Evidence on Environmental Regulations and Industry Location." Journal of the Environment and Development. 13(1): 6-41.

Cole, M.A. 2004. "U.S. Environmental Load Displacement: Examining Consumption, Regulations and the Role of NAFTA." Ecological Economics 48(4): 439-450.

Copeland, B., and M.S. Taylor. 2005. Trade and the Environment: Theory and Evidence. Princeton, NJ: Princeton University Press.

Creason, J., M. Fisher, S. Semenova, and S.F. Stone. 2005. "The Environmental Impacts of Trade Liberalization: A Quantitative Analysis for the United States Using TEAM." Agricultural and Resource Economics Review 34(1): 90-103.

Ederington, J., A. Levinson, and J. Minier. 2004. "Trade Liberalization and Pollution Havens." Advances in Economic Policy and Analysis 4(2): Article 6. Available at: http://www.bepress.com/bejeap/advances/vol4/iss2/art6.

Färe, Rolf, Shawna Grosskopf, Knox Lovell, and Carl Pasurka. 1989. Multilateral Productivity Comparisons when Some Outputs are Undesirable. Review of Economics and Statistics. 71, No.1 (February), 90-98. 
Färe, Rolf, Shawna Grosskopf, and Carl Pasurka, 2001, Accounting for air pollution emissions in measures of state manufacturing productivity growth, Journal of Regional Science, 41, 381-409.

Feenstra, R.C. 1996. "NBER Trade Database, Disk 1: U.S. Imports, 1972-1994: Data and Concordances." NBER Working Paper No. 5515. Cambridge, MA: NBER.

—. 1997. "NBER Trade Database, Disk 3: U.S. Exports, 1972-1994, with State Exports and Other U.S. Data." NBER Working Paper No. 5990. Cambridge, MA: NBER.

Gamper-Rabindran, S. 2006. "NAFTA and the Environment: What Can the Data Tell Us?" Economic Development and Cultural Change 54: 605-633.

Grossman, G.M., and A.B. Krueger. 1993. "Environmental Impacts of a North American Free Trade Agreement." in The Mexico-U.S. Free Trade Agreement (edited by P.M. Garber, Cambridge, MA: MIT Press) reprinted in Law and the Environment: An Interdisciplinary Reader (edited by R.V. Percival and D.C. Alevizatos, Philadelphia: Temple University Press, 1997).

Hettige, H., P. Martin, M. Singh, and D. Wheeler. 1995. "The Industrial Pollution Projection System." World Bank Policy Research Working Paper No. 1421. Washington, DC: World Bank Policy Research.

Hoekstra, R., and J. van den Bergh. 2002. "Structural Decomposition Analysis of Physical Flows in the Economy." Environmental and Resource Economics 23(3): 357-378.

_. 2003. "Comparing Structural and Index Decomposition Analysis." Energy Economics 25(1): 39-64.

Kahn, M.E. 2003. "The Geography of U.S. Pollution Intensive Trade: Evidence from 1959 to 1994." Regional Science and Urban Economics 33(4): 383-400.

Koo, A.Y.C. 1974. "Environmental Repercussions and Trade Theory." Review of Economics and Statistics 56(2): 235-244.

Levinson, A., and M.S. Taylor. Forthcoming. "Unmasking the Pollution Haven Effect." International Economic Review.

Leontief, W. 1970. "Environmental Repercussions and the Economic Structure: An Input-Output Approach." Review of Economics and Statistics 52(3): 262-271. 
Leontief, W., and D. Ford. 1972. "Air Pollution and the Economic Structure: Empirical Results of Input-Output Computations." Pages 9-29 in Input-Output Techniques. Edited by A. Brody and A.P. Carter. New York: North-Holland.

Meade, D.S. 2000. "Information Workers in the 'New Economy': Has IT Investment Had a Favorable Effect on the Demand for Skilled Labor?" Paper presented at the XIII International Conference on Input-Output Techniques at the University of Macerata, Italy, August 21-25.

Metcalf, G.E. 2007. "Energy Conservation in the United States: Understanding its Role in Climate Policy" Tufts University Economics Department working paper.

Miller, R.E., and P.D. Blair. 1985. Input-Output Analysis: Foundations and Extensions. Englewood Cliffs, NJ: Prentice-Hall.

Pasurka, C.A. 2003. "Changes in Emissions from U.S. Manufacturing: A Joint Production Perspective." Washington, DC: U.S. EPA.

Rose, A. 1999. "Input-Output Structural Analysis of Energy and the Environment." Pages 1164-1179 in Handbook of Environmental and Resource Economics. Edited by J. van den Bergh. Northampton, MA: Edward Elgar.

Schatan, C. 2003. "The Environmental Impact of Mexican Manufacturing Exports under NAFTA." In Greening NAFTA. Edited by D. Markell and J. Knox. Stanford, CA: Stanford University Press.

Turner, K., M. Lenzen, T. Wiedmann, and J. Barrett. 2007. "Examining the Global Environmental Impact of Regional Consumption Activities - Part 1: A Technical Note on Combining Input-Output and Ecological Footprint Analysis." Ecological Economics 62(1): 37-44.

U.S. Census Bureau. 2000. "Bridge between NAICS and SIC 1997." EC97x-C53. Washington, DC: U.S. Census Bureau.

U.S. EPA. 1998. "National Air Pollutant Emission Trends Procedures Document, 19001996." EPA-454/R-98-008. Research Triangle Park, NC: U.S. EPA Office of Air Quality Planning and Standards.

_ 2000. "National Air Pollutant Emission Trends, 1900-1998." EPA-454/R-00002. Research Triangle Park, NC: U.S. EPA Office of Air Quality Planning and Standards. 
Wiedmann, T., M. Lenzen, K. Turner, and J. Barrett. 2007. Examining the Global Environmental Impact of Regional Consumption Activities - Part 2: Review of Input-Output Models for the Assessment of Environmental Impacts Embodied in Trade." Ecological Economics 61(1): 15-26.

Wier, M., and B. Hasler. 1999. "Accounting for Nitrogen in Denmark: A Structural Decomposition Analysis." Ecological Economics 30(2): 317-331. 
Table 1. National Emissions Inventory Major Source Categories

\begin{tabular}{ll}
\hline & \multicolumn{1}{c}{ Category } \\
\hline 01 & Fuel combustion - electric utilities \\
$02^{*}$ & Fuel combustion - industrial \\
03 & Fuel combustion - other \\
$04^{*}$ & Chemical and allied products manufacturing \\
$05^{*}$ & Metals processing \\
$06^{*}$ & Petroleum and related industries \\
$07^{*}$ & Other industrial processes \\
08 & Solvent utilization \\
09 & Storage and transport \\
10 & Waste disposal and recycling \\
11 & On-road vehicles \\
12 & Non-road vehicles and engines \\
13 & Natural sources \\
14 & Miscellaneous \\
\hline
\end{tabular}

SOURCE: U.S. EPA (1998), p.4-4. Categories with asterisks $\left({ }^{*}\right)$ are included here as an approximation for manufacturing emissions.

Table 2. Ratio of True Manufacturing Pollution Using SIC Codes 20-39 To Approximation Using NEI Activity Codes

\begin{tabular}{ccccccccc}
\hline Pollutant & 1990 & $\ldots$ & 1996 & 1997 & 1998 & 1999 & 2000 & 2001 \\
\hline & & & & & & & & \\
All four & 0.77 & $\ldots$ & 0.73 & 0.74 & 0.74 & 0.73 & 0.72 & 0.73 \\
$\mathrm{SO}_{2}$ & 0.66 & $\ldots$ & 0.68 & 0.69 & 0.69 & 0.70 & 0.70 & 0.69 \\
$\mathrm{NO}_{\mathrm{X}}$ & 0.50 & $\ldots$ & 0.45 & 0.46 & 0.46 & 0.50 & 0.50 & 0.51 \\
$\mathrm{CO}$ & 0.95 & $\ldots$ & 0.88 & 0.89 & 0.89 & 0.89 & 0.90 & 0.90 \\
VOCs & 1.08 & $\ldots$ & 1.08 & 1.09 & 1.07 & 0.94 & 0.91 & 0.91 \\
\hline
\end{tabular}

NOTES: Each number in this table is total manufacturing pollution from the NEI calculated as the sum of pollution from all manufacturing SIC codes (20 through 39), divided by the total manufacturing pollution from the NEI approximated by the five starred activity codes in Table 1.

$\mathrm{SIC}=$ Standard Industrial Classification; $\mathrm{NEI}=$ National Emissions Inventory; $\mathrm{CO}=$ carbon monoxide; $\mathrm{SO}_{2}=$ sulfur dioxide $; \mathrm{NO}_{\mathrm{x}}=$ nitrogen oxides $; \mathrm{VOCs}=$ volatile organic compounds 
Table 3. Net Electricity Purchases from Offsite As a Share of Total Energy Consumed by Manufacturing

\begin{tabular}{lcccccc}
\hline & 1985 & 1988 & 1991 & 1994 & 1998 & 2002 \\
\hline Share purchased from offsite & 0.230 & 0.225 & 0.219 & 0.220 & 0.227 & 0.237 \\
\hline
\end{tabular}

SOURCE: Manufacturing Energy Consumption Survey (MECS), US Bureau of the Census.

Table 4. Scale, Composition, and Technique Effects for Criteria Pollutants: 1972-2001*

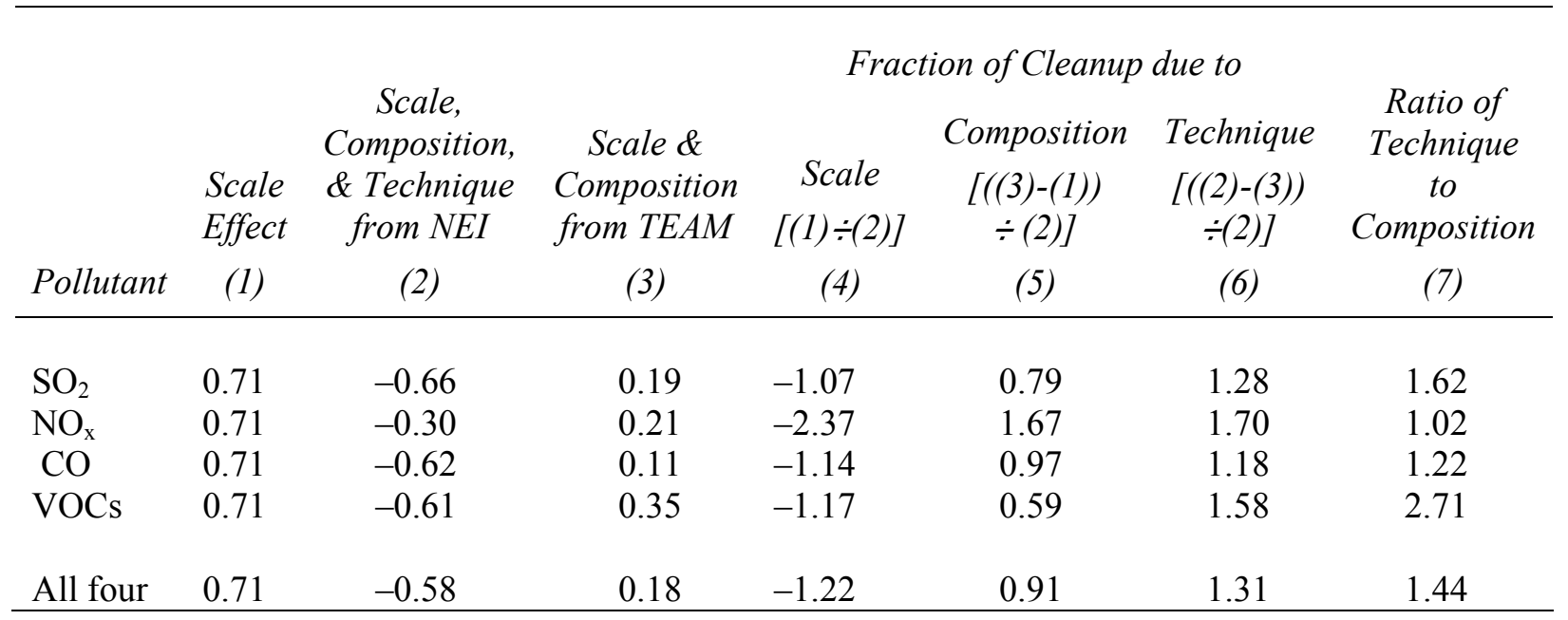

*Using industry-specific price deflators

NOTES: $\mathrm{SO}_{2}=$ sulfur dioxide; $\mathrm{NO}_{\mathrm{x}}=$ nitrogen oxides; $\mathrm{CO}=$ carbon monoxide; VOCs $=$ volatile organic compounds 
Table 5. Ratio of Technique to Composition Effects 1972-2001: Alternative Estimates

\begin{tabular}{|c|c|c|c|c|c|}
\hline Pollutant & $\begin{array}{c}\text { From } \\
\text { Table } 3 \\
\text { (1) }\end{array}$ & $\begin{array}{c}\text { Deflating Using } \\
\text { Producer Price } \\
\text { Index } \\
\text { (2) }\end{array}$ & $\begin{array}{c}\text { No } \\
\text { Computers } \\
\text { (3) }\end{array}$ & $\begin{array}{c}1972-1985 \\
\text { (4) }\end{array}$ & $\begin{array}{c}1985-2001 \\
(5)\end{array}$ \\
\hline $\mathrm{SO}_{2}$ & 1.62 & 7.43 & 5.89 & 5.41 & 1.29 \\
\hline $\mathrm{NO}_{\mathrm{x}}$ & 1.02 & 4.92 & 2.66 & 2.47 & 0.77 \\
\hline $\mathrm{CO}$ & 1.22 & 2.58 & 2.02 & 1.94 & 1.55 \\
\hline VOCs & 2.71 & 13.18 & 8.41 & 7.42 & 2.51 \\
\hline All four & 1.44 & 4.41 & 3.34 & 3.14 & 1.38 \\
\hline
\end{tabular}

NOTES: $\mathrm{SO}_{2}=$ sulfur dioxide $; \mathrm{NO}_{\mathrm{x}}=$ nitrogen oxides; $\mathrm{CO}=$ carbon monoxide VOCs $=$ volatile organic compounds 
Table 6. Percentage Difference between Pollution Predicted by Total Imports and Industry-Specific Prediction: The Composition Effect, 1972-2001

\begin{tabular}{|c|c|c|c|c|}
\hline & & $\begin{array}{l}\text { Using Direct } \\
\text { Emissions } \\
\text { Coefficients }\end{array}$ & $\begin{array}{r}\text { Using } 1 \\
\text { Requiren } \\
\text { Co }\end{array}$ & $\begin{array}{l}l \text { Domestic } \\
\text { ts Emissions } \\
\text { cients }\end{array}$ \\
\hline & $\begin{array}{l}\text { U.S. manufacturing } \\
\text { shipments }\end{array}$ & All Imports & All Imports & $\begin{array}{l}\text { Non-OECD } \\
\text { Imports }\end{array}$ \\
\hline Pollutant & (1) & (2) & (3) & (4) \\
\hline $\mathrm{SO}_{2}$ & -0.299 & -0.669 & -0.439 & -0.504 \\
\hline $\mathrm{NO}_{\mathrm{x}}$ & -0.282 & -0.675 & -0.437 & -0.510 \\
\hline $\mathrm{CO}$ & -0.342 & -0.646 & -0.282 & -0.191 \\
\hline VOCs & -0.192 & -0.607 & -0.443 & -0.505 \\
\hline $\begin{array}{l}\text { Sum of } 4 \text { air } \\
\text { pollutants from } \\
\text { section } 1\end{array}$ & -0.300 & -0.656 & -0.355 & -0.351 \\
\hline PM10 & -0.292 & -0.723 & -0.452 & -0.576 \\
\hline BOD & -0.226 & -0.819 & -0.812 & -0.837 \\
\hline TSS & -0.233 & -0.740 & -0.711 & -0.760 \\
\hline Toxic air & -0.220 & -0.686 & -0.552 & -0.491 \\
\hline Toxic water & -0.109 & -0.679 & -0.622 & -0.729 \\
\hline
\end{tabular}

NOTES: OECD = Organisation for Economic Co-operation and Development; $\mathrm{SO}_{2}=$ sulfur dioxide; $\mathrm{NO}_{\mathrm{x}}=$ nitrogen oxides; $\mathrm{CO}=$ carbon monoxide; VOCs $=$ volatile organic compounds; PM10 = particulates with a diameter of $10 \mu \mathrm{m}$ or less; $\mathrm{BOD}=$ biological oxygen demand; $\mathrm{TSS}=$ total suspended solids 
Table 7. Share of the Composition Effect Explained by Trade, 1972-2001

\begin{tabular}{lccc}
\hline & $\begin{array}{c}\text { Using Direct } \\
\text { Emissions Coefficients }\end{array}$ & $\begin{array}{c}\text { Using Total Domestic Requirements } \\
\text { Emissions Coefficients }\end{array}$ \\
\cline { 2 - 4 } & & & \\
\multicolumn{1}{c}{ Pollutant } & All Net Imports & All Net Imports & Non-OECD Net Imports \\
& $(1)$ & $(2)$ & $(3)$ \\
$\mathrm{SO}_{2}$ & & & \\
$\mathrm{NO}_{2}$ & 0.047 & 0.530 & 0.315 \\
$\mathrm{CO}$ & 0.051 & 0.426 & 0.204 \\
$\mathrm{VOCs}$ & 0.022 & 0.989 & 0.561 \\
Sum of 4 air & 0.167 & 0.565 & 0.250 \\
pollutants from & & & \\
section 1 & 0.045 & 0.721 & 0.401 \\
PM10 & & & \\
BOD & 0.011 & 0.532 & 0.248 \\
TSS & -0.401 & -0.371 & -0.257 \\
Toxic air & -0.042 & 0.034 & 0.040 \\
Toxic water & 0.064 & 0.575 & -0.020 \\
\hline
\end{tabular}

Negative numbers indicate that the change in pollution content of exports is greater than that of imports, and that adding back net imports (subtracting exports) makes the resulting series even cleaner.

NOTES: OECD = Organisation for Economic Co-operation and Development; $\mathrm{SO}_{2}=$ sulfur dioxide; $\mathrm{NO}_{2}=$ nitrogen dioxide; $\mathrm{CO}=$ carbon monoxide; $\mathrm{VOCs}=$ volatile organic compounds; $\mathrm{PM} 10=$ particulates with a mean aerodynamic diameter of $10 \mu \mathrm{m}$ or less; BOD = biological oxygen demand; TSS = total suspended solids 


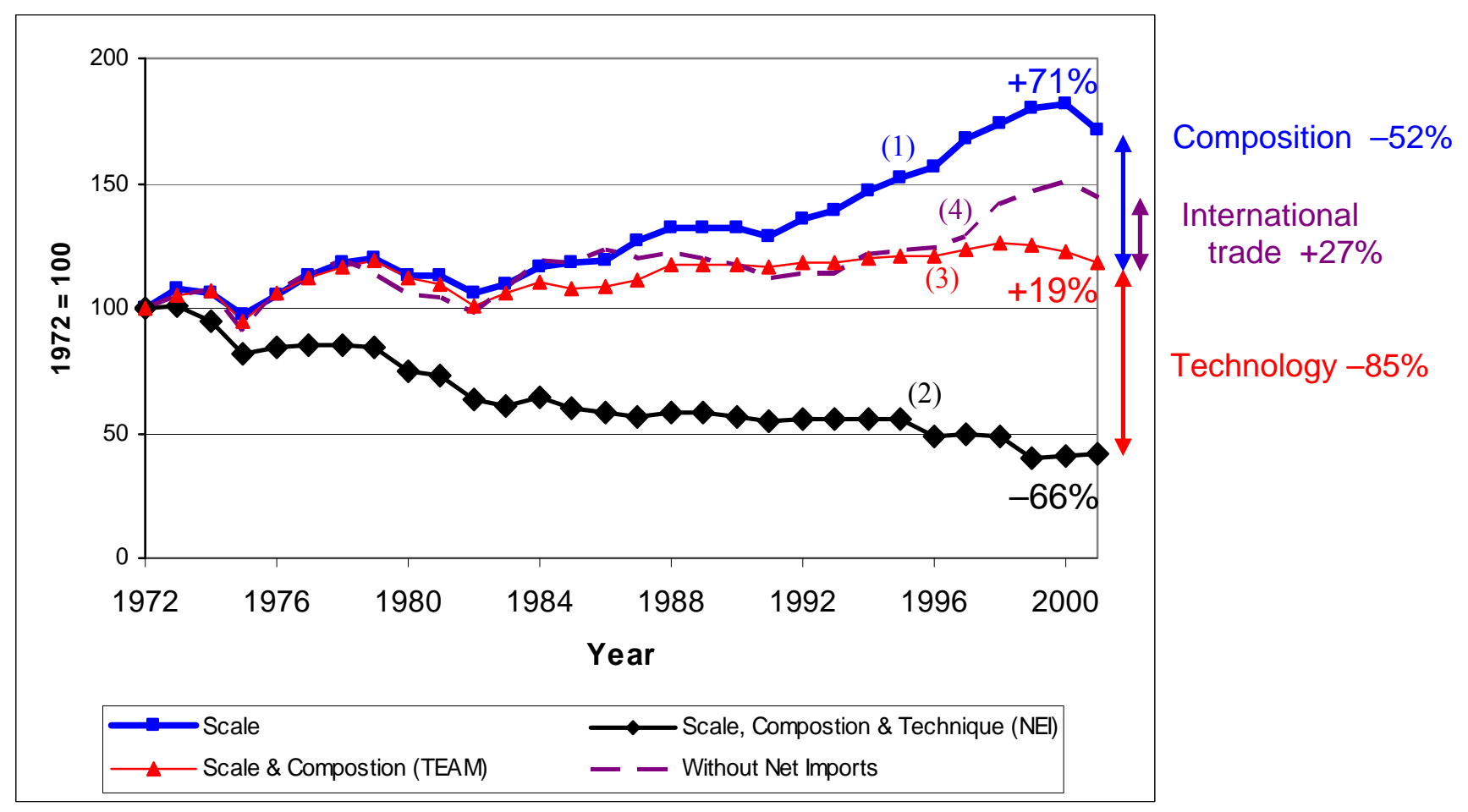

Figure 1. Sulfur Dioxide Emissions from U.S. Manufacturing

NOTES: NEI = National Emissions Inventory; TEAM = Trade and Environmental Assessment Model 


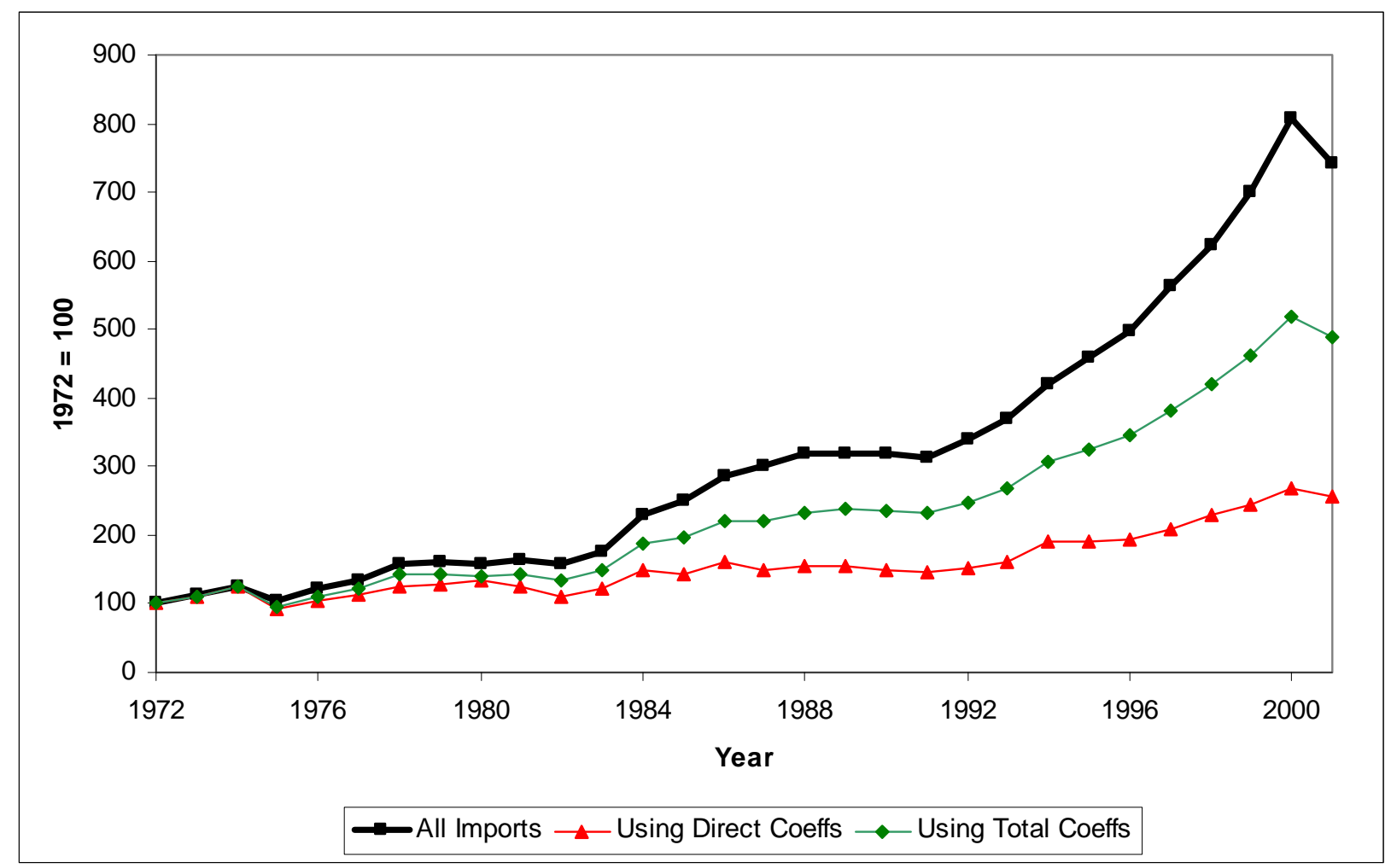

Figure 2. U.S. Imports from All Countries and Displaced Air Pollution*

* Sum of sulfur dioxide $\left(\mathrm{SO}_{2}\right)$, nitrogen oxides $\left(\mathrm{NO}_{\mathrm{x}}\right)$, carbon monoxide $(\mathrm{CO})$, and volatile organic compounds (VOCs) 